\title{
Redesigning a product: Strategy for alignment to mass production
}

\section{Rediseño de un producto: Estrategia para alineación a producción en serie}

\author{
OJEDA-ESCOTO, Pedro Agustín†* \\ Universidad Tecnológica de Aguascalientes, División de Electromecánica Industrial y Energías Renovables, Blvd. Juan \\ Pablo II 1302 Exhacienda la Cantera, C.P. 20200, Aguascalientes, México.
}

ID $1^{\text {st }}$ Author: Pedro Agustín, Ojeda-Escoto / ORC ID: 0000-0001-7282-4672, CVU CONACYT ID: 50027

DOI: $10.35429 / J B A B .2020 .7 .4 .12 .19$

Received September 22, 2020; Accepted December 15, 2020

\begin{abstract}
Today, companies dedicated to the design and manufacture of products seek to improve processes and procedures to provide better services. In addition to this, the development of products designed to meet specific needs plays an important role when feedback is obtained, in terms of design and functionality, from the end user for the consolidation of a product. Looking for such consolidation and identifying improvement opportunities, in the present paper a redesign was made based on specific criteria to align manufacturing to mass production. The theoretical framework is established taking the bases of Concurrent Engineering (CE) and Lean Manufacturing (LM), which allows to base the redesign of a scissor wagon (case study). The proposed design was structured under the approaches of cost reduction, quality improvement and characterization of geometry to reduce weight, allowed to define an architecture capable of being aligned to a mass production. The complete procedure to perform the redesign of the wagon and the analysis criteria used to conform such architecture are reported. Finally, the strategies defined for the inclusion of the new product to production and the geometry optimization results obtained by finite element analysis (FEA) are presented.
\end{abstract}

Design, Functionality, Production

\section{Resumen}

En la actualidad, empresas dedicadas al diseño y manufactura de productos buscan perfeccionar los procesos y procedimientos para ofrecer mejores servicios. Aunado a esto, el desarrollo de productos destinados a cubrir necesidades específicas juega un papel importante cuando se logra tener retroalimentación, en términos de diseño y funcionalidad, por parte del usuario final para la consolidación de un producto. Buscando tal consolidación e identificando oportunidades de mejora, en el presente artículo se realizó un rediseño en base a criterios específicos para alinear la fabricación a producción en serie. Se establece el marco teórico tomando las bases de la Ingeniería Concurrente (CE) y Manufactura Esbelta (LM), lo cual permite fundamentar el rediseño de un remolque de tijera (caso de estudio). El diseño propuesto fue estructurado bajo los enfoques de reducción de costos, mejora de calidad y caracterización de geometría para reducir peso, permitió definir una arquitectura capaz de ser alineada a una producción en serie. Se reporta el procedimiento completo para realizar el rediseño del remolque y los criterios de análisis utilizados para conformar dicha arquitectura. Finalmente, se presentan las estrategias definidas para la inclusión del nuevo producto a producción y los resultados de optimización de geometría obtenidos por análisis de elemento finito (FEA).

Diseño, Funcionalidad, Producción

Citation: OJEDA-ESCOTO, Pedro Agustín. Redesigning a product: Strategy for alignment to mass production. JournalBusiness Administration -Marketing; Accounting. 2020. 4-7: 12-19

\footnotetext{
* Correspondence to Author (pedro.ojeda@utags.edu.mx)

$\dagger$ Researcher contributing as first author.
} 


\section{Introduction}

Most of the structured methodologies to generate redesign seek to renew products from a particular approach, to mention a few: assembly, manufacturing, production, design for $\mathrm{X}$. On the other hand, few defined approaches to global redesign other than those already mentioned have been addressed systematically.

Taking traditional research as a starting point, in his work Pugh [1] presents a novelty of his Total Design Model to face the redesign. Some other design models are based on the execution and evaluation stages, or on the optimization of an initial alternative ([2], [3]).

Lefever \& Wood [4] define redesign as a design process applied to an existing product or detailed prototype or concept. They also add that this process uses a variety of techniques such as models, graphics, diagrams, guidelines, etc. to analyze and fully understand a product. On the other hand, Otto and Wood [5] express that in reverse engineering the redesign process begins with the observation of the product, segmenting it, analyzing it and documenting it in terms of functionality, geometry, physical principles, manufacturing and assembly feasibility. They also add that the intention of this procedure is to fully understand the product and represent the current demands.

Studies by (Li et al [6]; Iyer et al [7]; Lou et al. [8]; Han \& Lee [9]; Howard et al [10]) define and treat redesign as a resolution of conflicts between current product needs and previous design capabilities; they also document that innovative products are only introduced when there are major conflicts between client needs and existing products.

This paper reports the procedure and results of the redesign done to a scissor wagon (case study) structured in the approaches of cost reduction, quality improvement and geometry characterization to reduce weight. It also reports the results obtained from the finite element analysis made to the mentioned wagon to optimize its final architecture. Finally, defined strategies to align manufacturing to production are mentioned.

\section{Theoretical Framework}

\subsection{Concurrent Engineering}

The beginnings of Concurrent Engineering (CE) emerged from the aerospace industry, where all processes are governed by two main ideas:

- $\quad$ All components and elements of the final product must be considered from the earliest stages of design.

- $\quad$ All the design activities preceding the achievement of the product must be happening at the same time, that is to say, they must be advancing simultaneously in the process.

Once the EC has been contextualized, which is currently closely related to the development of new products, it can be defined as the process of developing new products in which all areas must be involved, working accordingly in the creation of the product. This involvement ranges from the contribution of ideas to the matching and readjustment of information to achieve the agreed product. Apart from being a mere work philosophy, the EC involves a series of work techniques that allow to shorten considerably the time of development of a product, allowing to reduce its costs, increase the quality and, therefore, to improve it.

Common problems that make necessary the implementation of the $\mathrm{CE}$ in the design or redesign of a new product:

- Increased product variety and technical complexity that prolongs the product development process and makes it difficult to predict the impact of design decisions on the functionality and performance of the final product.

- Increase the global competitive pressure resulting from the emerging concept of reengineering.

- The need for a rapid response to changing consumer demand.

- $\quad$ The need for a shorter product life cycle.

- Large organizations with several departments working on the development of numerous products at the same time.

- New and innovative technologies that emerge at a very high rate, making the new product technologically obsolete in a short period of time. 


\subsection{Lean Manufacturing}

Lean Manufacturing (LM) involves several tools that help eliminate all operations that do not add value to the product/service and/or process, increasing the value of each activity performed and eliminating what is not required, reducing waste and improving operations.

The LM system has been defined as a philosophy of manufacturing excellence, based on:

\section{- $\quad$ The planned elimination of all types of waste. \\ - Continuous improvement. \\ - The permanent improvement of Productivity and Quality.}

The main objectives of LM are to implement a philosophy of continuous improvement that allows companies to reduce costs, improve processes and eliminate waste to increase customer satisfaction and maintain the profit margin. It provides companies with tools to survive in a global market that demands higher quality, faster delivery at lower prices and in the required quantity. Specifically, the LM:

- $\quad$ Reduces the waste stream dramatically.

- $\quad$ Reduces inventory and production floor space.

- $\quad$ Creates more robust production systems.

- Creates appropriate material delivery systems.

- Improves plant layouts to increase flexibility.

The implementation of LM is important in different areas, since different tools are used, so it benefits the company and its employees. Some of the benefits it generates are:

- $\quad$ Reduction, at least $50 \%$ in production costs.

- $\quad$ Reduction of inventories and lead time.

- Better quality and less labour.

- Increased equipment efficiency and reduced waste.

- Overproduction and decrease in waiting time.

- Transportation, processes, inventories and movement of final product.

\section{Data analysis}

The development of all research consists of extracting the information by following a methodology, the architecture of the product in question and the procedural detail of the same in order to understand it.

It is important to mention the methodology needed to be able to pose the problem of an investigation; that is, to formulate or pose a problem requires a previous analysis of the knowledge about its nature, that is, to have considered the important or relevant facts and concepts according to which it is possible to define in a synthetic way the problem in question. It is also worth mentioning that many times, in order to benefit from the progress of an investigation, it is necessary to follow methodologies that have already been defined or to follow some variant based on those already mentioned. Figure 1 presents the methodology proposed for the development of this work.

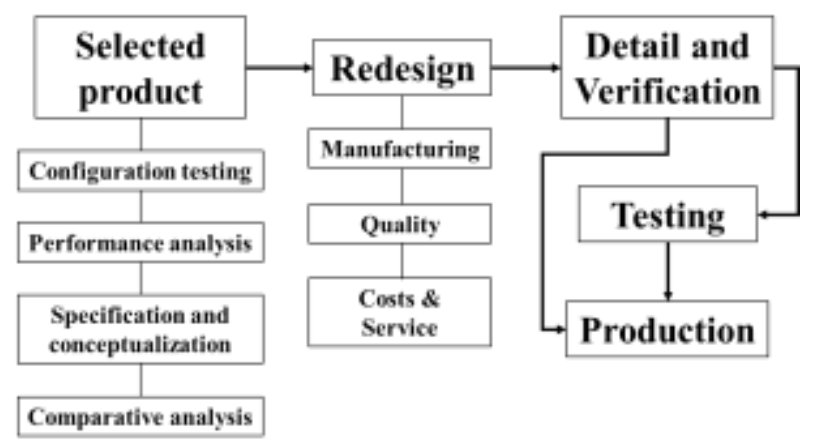

Figure 1 Research methodology Source: Own Production

\subsection{Case Study}

As a case study for the development of this research, the redesign of a scissor wagon is presented. This wagon is manufactured and distributed by a $100 \%$ Mexican company dedicated to offering, within its main activities, integral solutions in the agricultural area.

\subsubsection{Solution approach}

In order to define a new design of the wagon, the following approaches were considered: cost reduction, quality improvement, geometry characterization to reduce weight; based on the mentioned approaches, several configurations were proposed and reviewed to provide a solution to the problem under study. 
Several configurations were conceptualized taking into account the defined approaches and finally the final architecture of the scissor wagon was generated. Figure 2 presents the final proposed geometry.

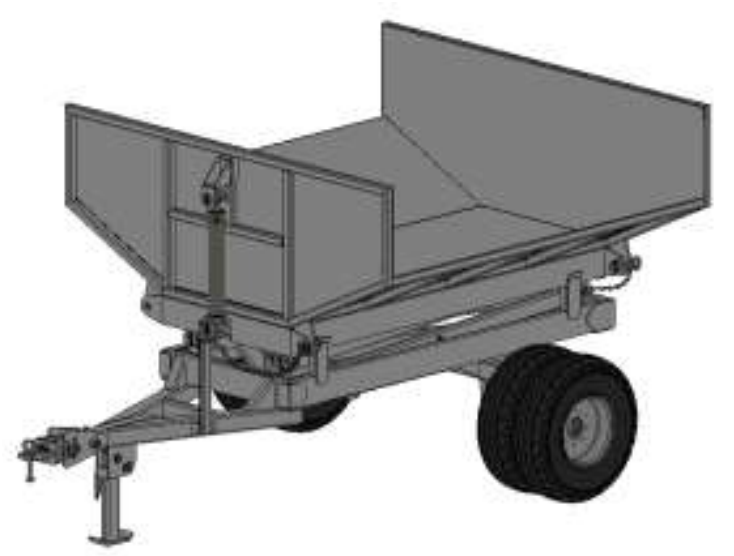

Figure 2 Case study: scissor wagon

Source: Own Production

\subsubsection{Geometry optimization}

Once the final architectural geometry was selected, finite element analyses were performed to validate and optimize (for assembly purposes) that architecture. The mesh of the models was generated based on the existing dimensional relations between the components of the assembly and the load conditions proposed for the analysis were determined based on the solicitations that are presented in the normal work of the wagon (see figure 3 ).
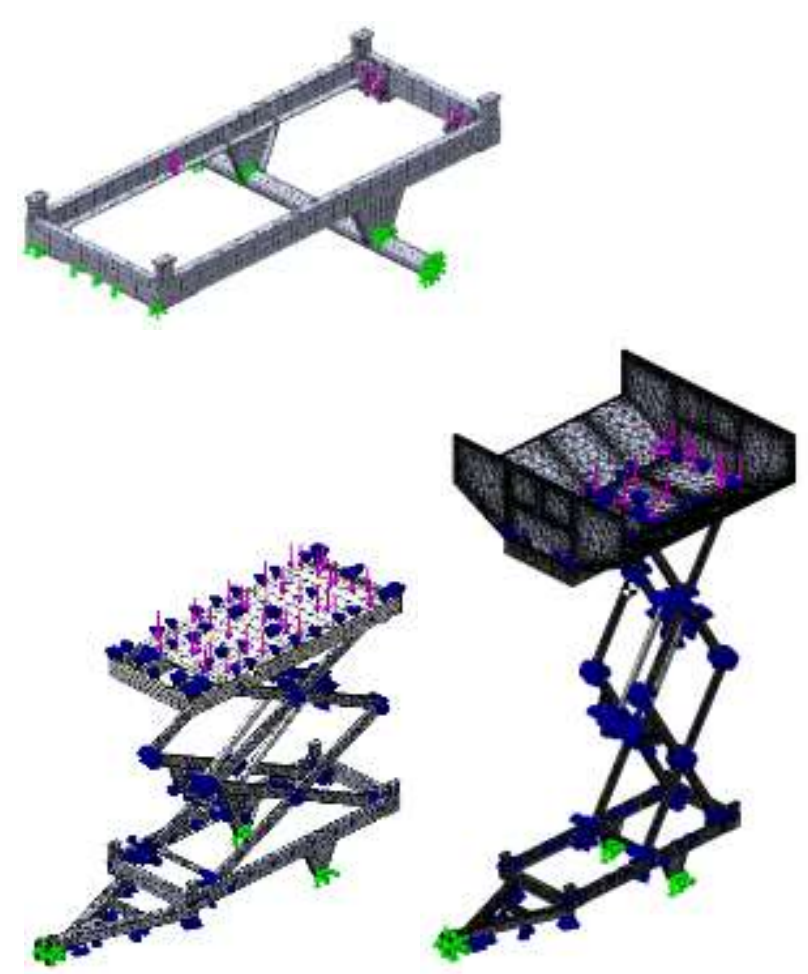

Figure 3 Application of border conditions

Source: Own Production

ISSN 2531-3002

RINOE® All rights reserved
The analysis by finite element was done in several stages, in each of them different criteria were taken for analysis and also several positions of height of the wagon were defined based on the normal work it performs. The following images show the results obtained from the final architecture.

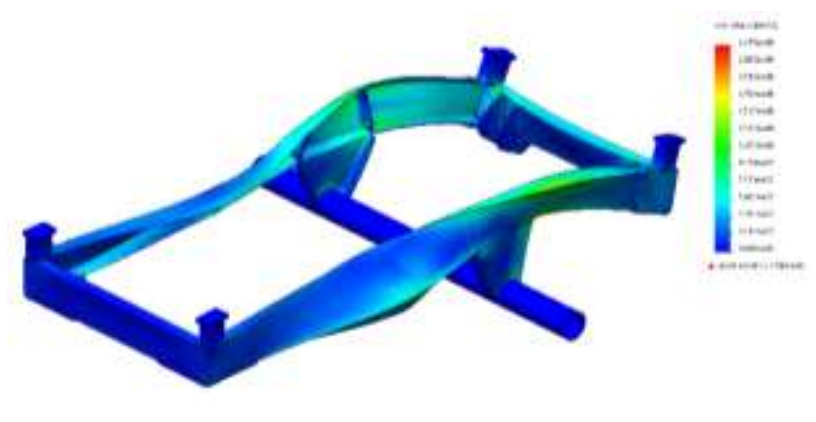

Figure 4 FEA results - Phase 1

Source: Own Production
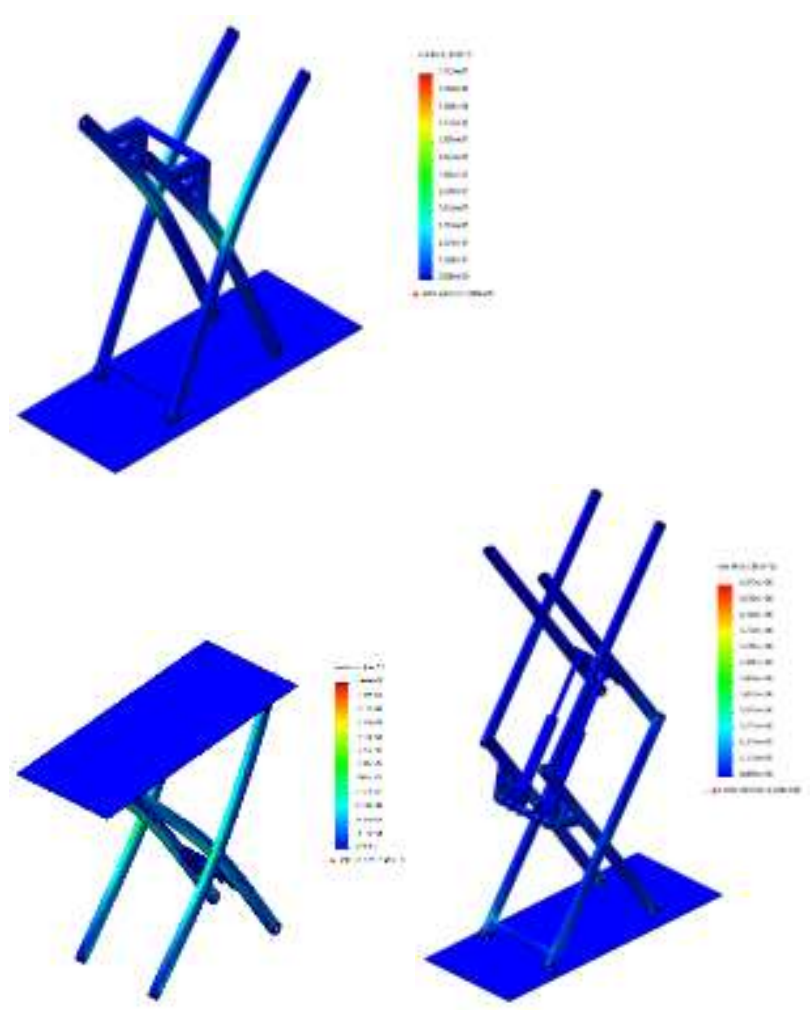

Figure 5 FEA results - Phase 2

Source: Own Production 


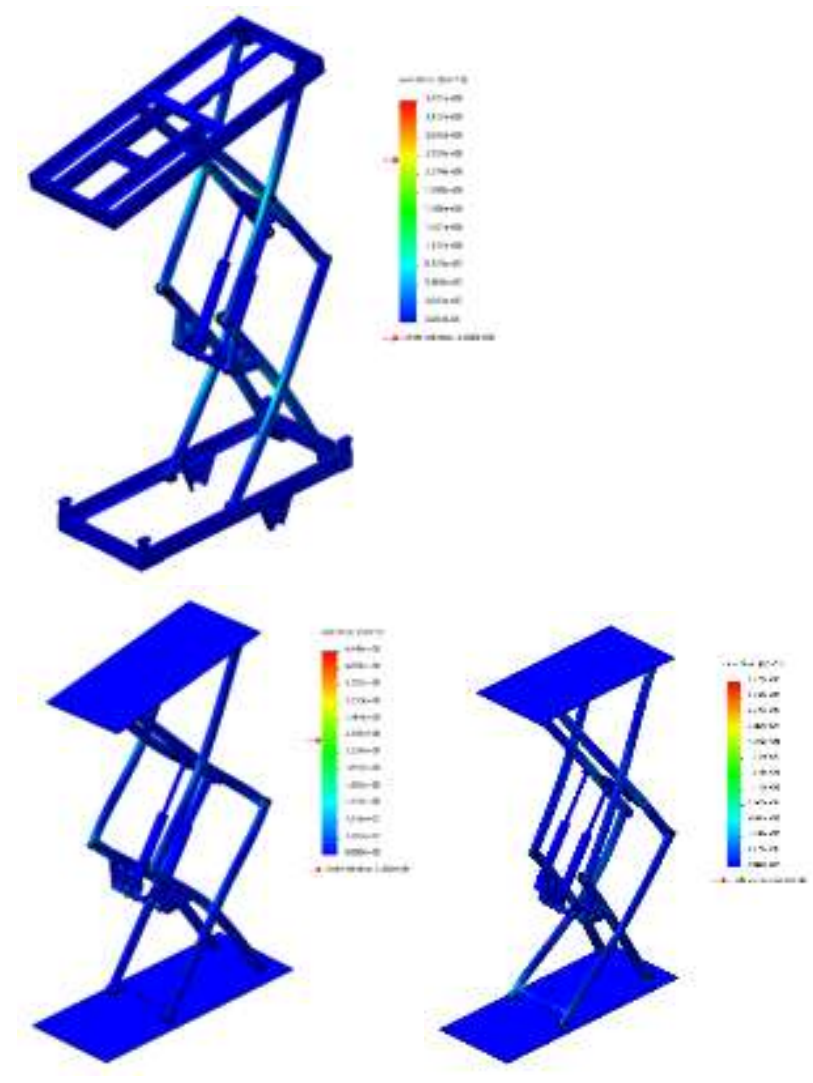

Figure 6 FEA results - Phase 3

Source: Own Production
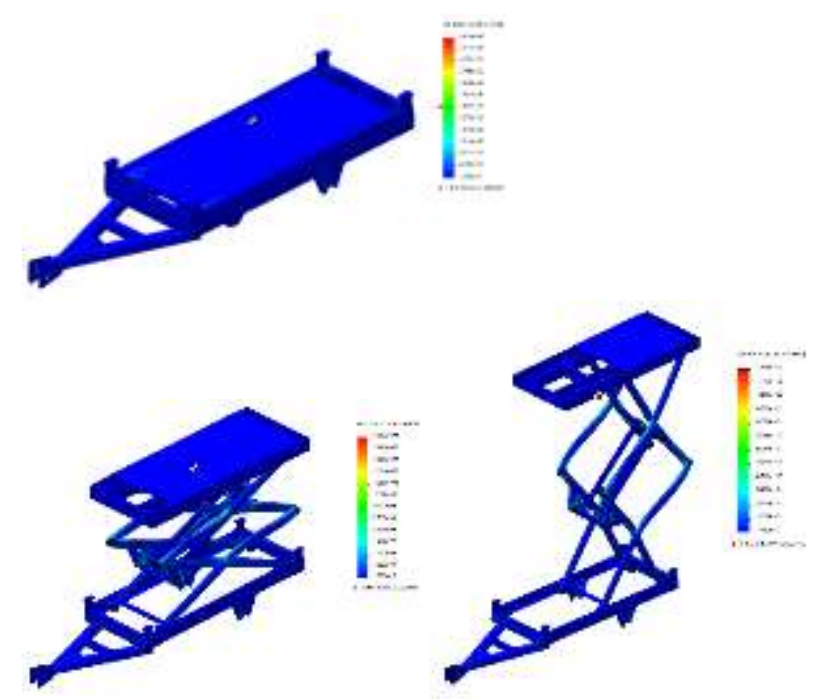

Figure 7 FEA results - Phase 4 Source: Own Production
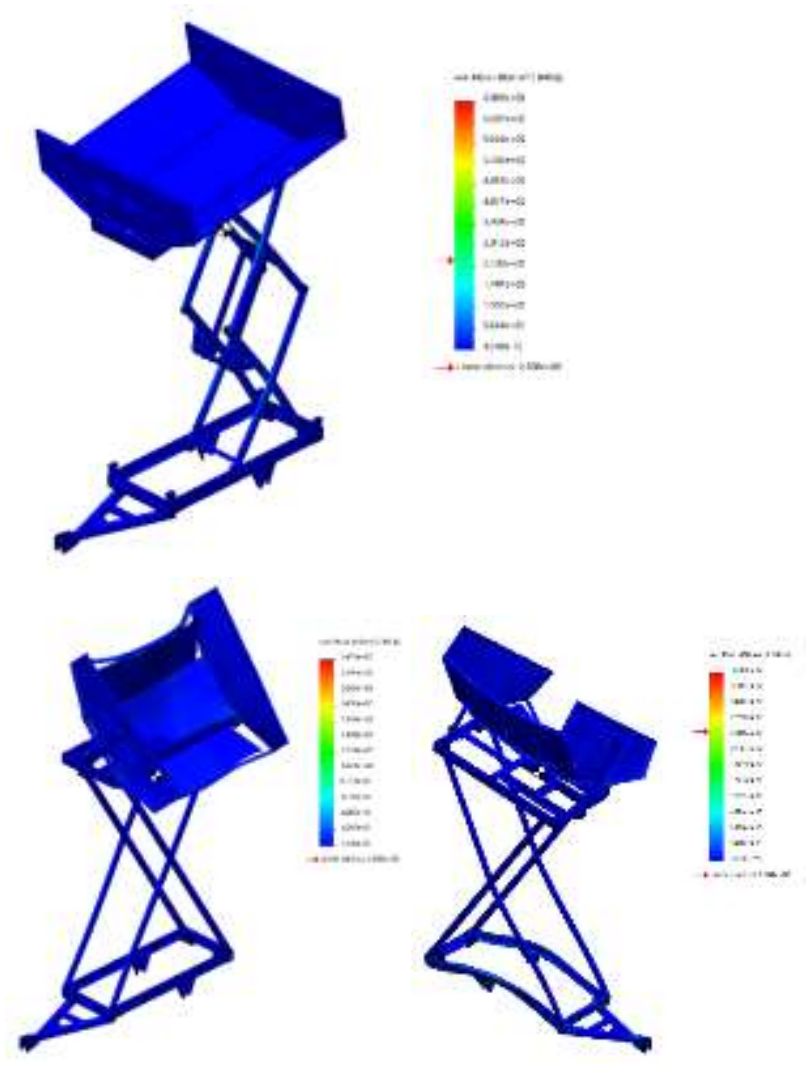

Figure 8 FEA results - Phase 5

Source: Own Production

\section{Results and Discussion}

The stress study carried out on the model of the wagon allows us to demonstrate that each and every one of the elements that make it up present stress magnitudes below the permissible elastic limit of the material.

It was even possible to optimize some elements and comply with the design approaches that were taken into account to define the final architecture of the wagon, these are: cost reduction, quality improvement, geometry characterization to reduce weight.

It is also important to mention that the stress magnitudes are within the normal deformation ranges so, for the time being, they can be neglected in order to continue with the manufacturing of the final prototype.

With these results it was also possible to define the assembly and disassembly procedures of the wagon; likewise, strategies were defined to align the manufacture of the prototype to mass production. In the following section, the strategies mentioned are presented. 


\subsection{Strategies for production alignment}

Once the new architecture of the trailer was defined and the tests of the product concept were carried out, the following strategies were defined to align it to production, taking into account product image and marketing (due to confidentiality issues of the company, these strategies are mentioned in a very global way).

\subsubsection{Product development and prototype evaluation}

The first step to think about defining strategies to align a product to production is to corroborate that the concept of the product passes a commercial test (projection of the customer's special requirement). Once this experience has been approved, we move on to the product development stage, during which the development and engineering areas transform the concept into a physical product.

\subsubsection{Marketing strategy}

The development of the marketing strategy refers to the design of an initial strategy for the new product, it was taken based on the final concept and involves the following segments:

\section{- $\quad$ Market participation. \\ - $\quad$ Probable price of the product. \\ - $\quad$ Positioning of the product. \\ - Sales objective.}

The business analysis implies the revision of the estimations made with respect to sale - cost - utility of the new product and thus to foresee that the proposed objectives are satisfied. To determine this strategy, it was also necessary to review the design and testing of various configurations by the development and engineering area.

\subsubsection{Commercial viability strategy}

Once the final concept of the product is defined, it is possible to evaluate the commercial attractiveness of the defined proposal. The commercial analysis implies the exploration of sales and costs to determine if the established objectives will be met.
Having the sales projection, the Brand Manager and the distribution area estimate the costs and benefits expected from the product. Finally, the areas of development, production, accounting and finance will estimate the final costs, including also those of marketing; with this information it is possible to make the analysis of the financial attractiveness of the new product.

\subsubsection{Market test strategy}

Once the product has passed the functionality tests and consumer approval, the next step is to launch it on the market. Market testing is the phase where the product is introduced to a more realistic market environment. The established amount of these marketing tests depends on the estimated sales projection.

If it is assumed that projecting high costs means that market testing will take a long time, then projecting low costs in product development and introduction will provide confidence that the product will be successful.

\subsubsection{Marketing strategy}

Market testing provides product managers with the information needed to make the final decision on launching a new product.

The launch of a new product should be considered:

- The most suitable time for the introduction of the product.

- $\quad$ Define the market scope, that is, launch in one place, in one region or in several; as well as evaluate the national and international market.

- $\quad$ Define distribution channels.

- $\quad$ Reliable sales projections and detailed marketing plans.

Figure 9 shows the global diagram of the defined strategies. 


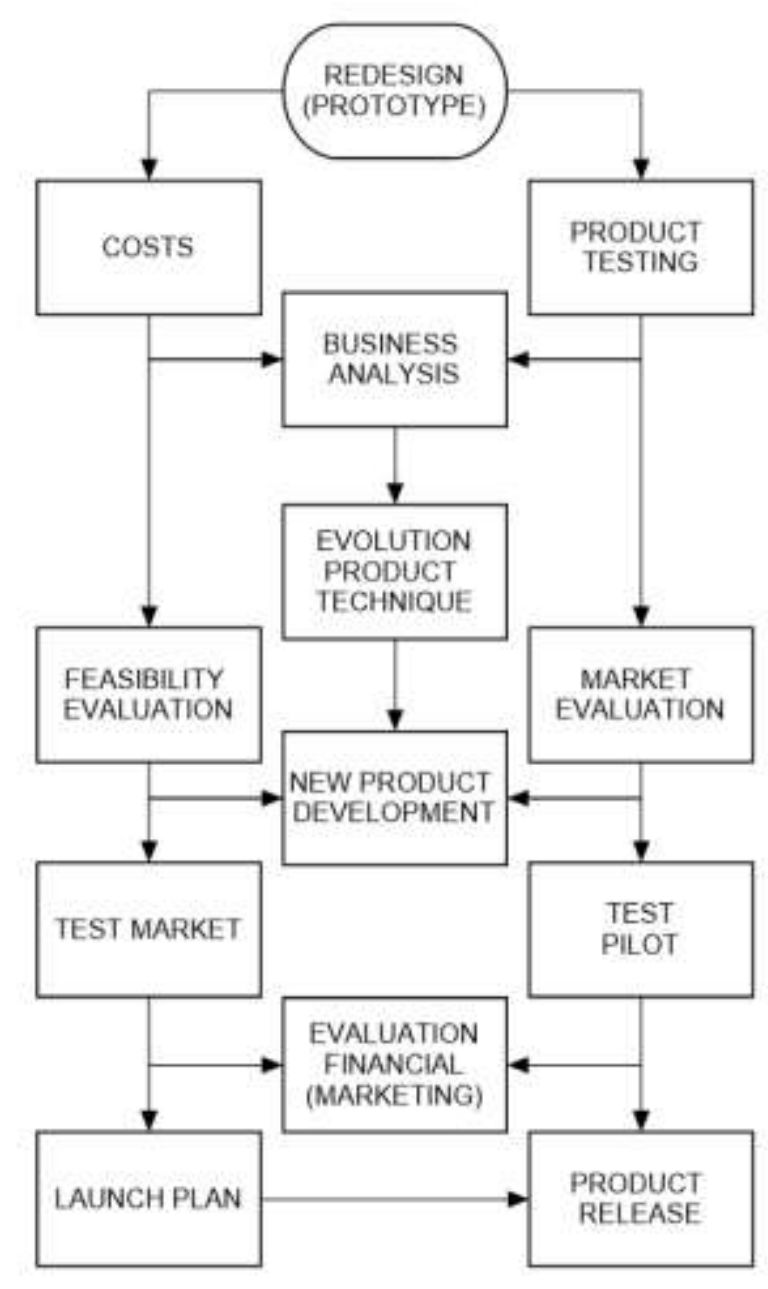

Figure 9 Production strategies

Source: Own Production

\section{Conclusions}

The development and implementation of methodologies for design or redesign of products based on new technologies, increases the chances of alignment in the market and the increase of knowledge and technology transfer to the industrial sector. Designing is establishing and defining relevant solutions and structures, for problems that have not been solved before or new solutions posed in a different way for problems that have been previously solved. Advances in computer and technology analysis allow engineers and researchers to have effective diagnostic and simulation tools that facilitate, at a given time, the design, redesign or optimization of a mechanical system.

In this paper, the optimization of geometry of a scissor trailer and the results of the finite element analysis were presented as a case study that helped to define the redesign of the final architecture of this trailer.
Finally, the strategies defined for the alignment of the new product developed to production, taking into account sales projections, product image and marketing, were presented.

\section{Thanks}

The author of this paper wishes to thank the technical, economic and logistical support of the Industrial Electromechanics and Energy Division of the Universidad Tecnológica de Aguascalientes.

\section{References}

[1] Pugh, S. Total Design. Addison Wesley, Great Britain, ISBN 0-201-41639-5, 1990.

[2] Ullman, D. G. The Mechanical Design Process, Mc. Graw-Hill, New York, ISBN 0-07112871-9, 1992.

[3] Ulrich, K.T., Eppinger, S.D. Product design and development, Mc. Graw-Hill, International Editions, ISBN 0-07-113742-4, 1995.

[4] Lefever, D.D., Wood, K.L., Design for Assembly Techniques in Reverse Engineering and Redesign, ASME Design Theory and Methodology Conference, 1996.

[5] Otto, K.N., Wood, K.L., Product Evolution: A Reverse Engineering and Redesign Methodology, Research in Engineering Design, Springer-Verlag London Limited, 10: 226-243, 1998.

[6] Li, Z.S., Kou, F.H., Cheng, X.C., \& Wang, T., Model-based product redesign, International Journal of Computer Science and Network Security, 6-1: 99-102, 2006.

[7] Iyer, N., Kalyanaraman, Y., Lou, K., Janyanti, S., Ramani, K., A reconfigurable 3D engineering shape search system part I: shape representation, Proceedings of the ASME International Design Engineering Technical Conferences and Computers and Information in Engineering Conference, 2003. 
[8] Lou, K., Jayanti, S., Iyer, N., Kalyanaraman, Y., Prabhakar, S., Ramani, K., A reconfigurable 3D engineering shape search system part II: database indexing, retrieval, and clustering, Proceedings of the ASME International Design Engineering Technical Conferences and Computers and Information in Engineering Conference, 2003.

[9] Han, Y.H., Lee, K., A case-based framework for reuse of previous design concepts in conceptual synthesis of mechanisms, Computers in Industry, Elsevier Ltd. Journals, 57-4: 305318, 2006.

[10] Howard, T.J., Culley, S.J., Dekoninck, E.A., Reuse of ideas and concepts for creative stimuli in engineering design, Journal of Engineering Design, 22-8: 565-581, 2011.

[11] Smith, S., Smith, G., Shen, Y., Redesign for product innovation, Design Studies, Elsevier Ltd. Journals, 33-2: 160-184, 2012.

[12] Van Eldonk, S.J.M., Alberts, L.K., Bakker, R.R., Dikker, F., Wognum, P.M., Redesign of technical systems, Knowledge-Based Systems, Elsevier Ltd. Journals, 9: 93-104, 1996.

[13] Adam, A., Cosma, C., Cosma, A., Pop, A., Redesigning a product using modern CADCAM software, 8th International Conference Interdisciplinary in Engineering, Elsevier Ltd., Procedia Technology 19: 221-227, 2015.

[14] Winner, R.I., Pennell, J.L., Bertrand, H.E., Slusarzuk, Marko, M.G., The Role of Concurrent Engineering in Weapon Systems Acquisition, Institute of Defense Analysis, Report R-338, EUA, 1988.

[15] Cleetus, K.J., Definition of Concurrent Engineering, CERC Technical Report Series, Technical Memoranda (CERC-TM-92-003), EUA, 1992.

[16] Chase, R.B., Aquilano, N.J., Jacobs, F.R., Production and Operations Management, Mc Graw-Hill International Editions, ISBN 978970-10-7027-7, 2006. 